\title{
Ovalbumin induces natural killer cells to secrete Th2 cytokines IL-5 and IL-13 in a mouse model of asthma
}

\author{
ZHANGBO $\mathrm{CHEN}^{1}$ and $\mathrm{LU}^{\mathrm{W}} \mathrm{WANG}^{2}$ \\ ${ }^{1}$ Department of Pathogen Biology and Immunology, Shenzhen University School of Medicine, Shenzhen, Guangdong 518060; \\ ${ }^{2}$ Department of Physiology and Chinese-German Stem Cell Center, Tongji Medical College, Huazhong University of \\ Science and Technology, The Key Laboratory for Drug Target Researches and Pharmacodynamic Evaluation of \\ Hubei Province, Wuhan, Hubei 430030, P.R. China
}

Received April 8, 2018; Accepted February 14, 2019

DOI: $10.3892 / \mathrm{mmr} .2019 .9966$

\begin{abstract}
Asthma is a chronic lung disease characterized by an imbalance of T-helper (Th)1/Th2 cells and their cytokine profiles. Natural killer (NK) cells constitute a considerable subset of the lymphocyte population in the lungs, and provide protection against respiratory infection by fungi, bacteria and viruses. However, the mechanism by which NK cells are involved in asthma remains to be fully elucidated. The present study analyzed the dynamic changes of NK cells and their subsets during the development of the ovalbumin (OVA)-induced allergic airway response. Lung tissues were histologically examined for cell infiltration and mucus hypersecretion. The number, activity and cytokine-secreting ability of NK cells was determined by flow cytometry. The results showed that the percentage of NK cells in the lung was decreased following OVA sensitization and challenge. However, NK cells exhibited enhanced activity and secreted more Th2 cytokines (IL-5 and IL-13) following OVA challenge. Furthermore, the proportion of $\mathrm{CD}_{11 b^{-}} \mathrm{NK}$ subsets increased with the development of asthma,

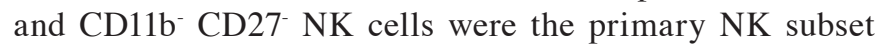
producing Th2 cytokines. These findings suggest that, although NK cells are not the crucial type of lymphocytes involved in asthma, OVA induces NK cells to secrete Th2 cytokines that may be involved in the pathogenesis of asthma.
\end{abstract}

\section{Introduction}

Allergic asthma is a chronic airway disorder characterized by symptoms that include wheeze, cough, shortness of breath and chest tightness $(1,2)$. An estimated 300,000,000 individuals worldwide suffer from asthma which imposes a substantial economic burden on individuals and society (3). Cumulative evidence from human and animal model systems suggest that

Correspondence to: Dr Zhangbo Chen, Department of Pathogen Biology and Immunology, Shenzhen University School of Medicine, 3688 Nanhai Avenue, Shenzhen, Guangdong 518060, P.R. China E-mail: cat_love_guai@163.com

Key words: asthma, natural killer cells, cytokine asthma is associated with polarized T-helper (Th)2 responses to inhaled allergens $(4,5)$. Th2 cells secrete cytokines, including interleukin (IL)-4, IL-5 and IL-13, which induce isotype switching to immunoglobulin E (IgE) by B lymphocytes. The cross-linking of allergen-specific $\operatorname{IgE}$ bound to the receptor on the surface of mast cells and basophils results in the release of histamine and leukotriene, and leads to bronchoconstriction and vasodilation. The earlier contact between an allergen and innate immune cells, including dendritic cells (DCs), natural killer (NK) cells and bronchial epithelial cells, is thought to direct the subsequent antigen-specific T-cell response $(6,7)$. Inhaled allergens activate the Toll-like receptor (TLR) class of pattern recognition receptors involved in innate immunity and induce the synthesis of innate cytokines for initiating the development of Th2 adaptive responses $(8,9)$.

NK cells are critical in innate immune responses and make up $10 \%$ of resident lymphocytes in the lungs of humans and mice (10). Evidence has emerged that NK cells are important in various lung diseases. NK cells are best noted for their ability to produce interferon (IFN) $-\gamma$, however, they also produce a number of other cytokines, including tumor necrosis factor (TNF)- $\alpha$, granulocyte-macrophage colony-stimulating factor, IL-5, IL-13 and C-C motif chemokine ligand 5/RANTES (11). Human NK cells can be divided into four subsets based on the relative expression of markers CD16 and CD56. The CD16 ${ }^{+}$ CD56- NK subset, the majority of which is in the peripheral blood, is potent cytotoxic cells, and the CD16- CD56 ${ }^{+} \mathrm{NK}$ subset is found mostly in the lymphoid organs and produces high levels of cytokines $(12,13)$. In mice, CD11b and CD27 reflect distinct population and functional specialization in human NK cells. The CD11b- CD27 $7^{+} \mathrm{NK}$ subset, which is typically observed in the bone marrow, is a potent producer of cytokines and is less cytotoxic than the $\mathrm{CD} 11 \mathrm{~b}^{+} \mathrm{CD} 27^{-} \mathrm{NK}$ subset that resides primarily in the spleen, peripheral blood and lungs $(14,15)$.

The present study examined the dynamic behavior of NK cells and their subsets during the development of asthma using an ovalbumin (OVA)-induced mouse model. The percentage of NK cells in the lung was decreased following OVA sensitization and challenge. However, the NK cells showed a high level of activation and secreted more Th2 cytokines than Th1 cytokines. In addition, an increased proportion of CD11b NK cells was observed in the process of OVA induction. 
CD11b CD27- NK cells were the primary NK subset producing Th2 cytokines. Together, these findings provide novel insights for understanding the mechanism of asthma.

\section{Materials and methods}

Mice. Female BALB/c mice (6-8 weeks old; $18-20 \mathrm{~g} ; \mathrm{n}=6$ each group) were purchased from Guangdong Medical Laboratory Animal Center, Foshan (Guangdong, China). The mice were housed in a $12 \mathrm{~h} \mathrm{light/dark}$ cycle at $22^{\circ} \mathrm{C}$ under specific pathogen-free conditions and allowed access to food and water ad libitum. The animal experiments were performed according to the Institutional Guidelines for the Animal Care and Use Committee of Shenzhen University (Shenzhen, China).

OVA-induced allergic asthma model. The mice were sensitized with an intraperitoneal (i.p.) injection of $10 \mu \mathrm{g}$ OVA (Grade V; Sigma-Aldrich; Merck KGaA, Darmstadt, Germany) emulsified in aluminium hydroxide gel (InvivoGen, San Diego, CA, USA) on days 0 and 7. On days 14-17 the animals were challenged with $6 \%$ OVA aerosol. The aerosol administrations were performed for $25 \mathrm{~min}$ using an ultrasonic nebulizer (Leyi Industry Co., Ltd., Shanghai, China). Animals in the control group received an i.p injection of PBS emulsified in $100 \mu \mathrm{l}$ of aluminium hydroxide gel and were challenged with PBS aerosols. All mice were sacrificed $24 \mathrm{~h}$ following the final OVA challenge for subsequent assays (Fig. 1).

Bronchoalveolar lavage fluid (BALF) collection. Tracheotomy was performed, and a cannula was inserted into the trachea. PBS $(0.6 \mathrm{ml} \times 2)$ was instilled into the left lungs following ligation of the right lungs, and BALF was collected. The cells in the BALF were centrifuged at $300 \mathrm{xg}$ at $4^{\circ} \mathrm{C}$ for $10 \mathrm{~min}$ in a cytocentrifuge and then stained with Wright-Giemsa (Quick Wright-Giemsa Stain, Jiancheng Bioengineering Institute, Nanjing, China). The cells were identified as macrophages, eosinophils, neutrophils and lymphocytes under magnification, x200 using a Leica DM LB microscope (Leica Microsystems, Inc., Buffalo Grove, IL, USA).

Blood collection. Blood samples were obtained from the retro-orbital venous plexus. The blood was stored at room temperature for $1 \mathrm{~h}$, then centrifuged at $1,500 \mathrm{x} g$ at room temperature for $15 \mathrm{~min}$. The serum was collected for IgE and OVA-specific IgE assays.

Lung histology. The right lung tissues were fixed in $4 \%$ paraformaldehyde, paraffinized, cut into $4-\mu \mathrm{m}$ sections, and then stained with hematoxylin and eosin for examining cell infiltration and with periodic acid-schiff for the detection of mucin in goblet cells (mucus-secreting cells) by light microscopy.

ELISA. The quantitation of cytokines IL-4, IL-5 and IL-13 in the BALF and the serum levels of $\mathrm{IgE}$ were measured by sandwich ELISA using paired antibodies (BD Biosciences, San Jose, CA, USA). The serum levels of OVA-IgE were measured using a mouse OVA-specific IgE ELISA kit (Cusabio Biotech, Wuhan, China). The sensitivity of detection was $4 \mathrm{pg} / \mathrm{ml}$ for IL-4, IL-5 and IL-13, and $5 \mathrm{ng} / \mathrm{ml}$ for IgE.
Lungs tissue preparation. The lungs from the mice, perfused with PBS containing $0.5 \mathrm{mM}$ EDTA, were immediately excised and cut into pieces. As collagenase digestion downregulates the density of CD27 on lymphocytes, the lung pieces were ground with a stirring rod accompanied with the addition of complete RPMI-1640 (Gibco; Thermo Fisher Scientific, Inc., Waltham, MA, USA) on a 200-mesh stainless steel gauze, as described previously (16). The cells were filtrated, centrifuged at $300 \mathrm{xg}$ at $4^{\circ} \mathrm{C}$ for $5 \mathrm{~min}$ and then resuspended in PBS.

Flow cytometric analysis. The cells isolated from the lungs were resuspended in PBS and the viable cells were counted using a solution of $0.4 \%$ Trypan blue in PBS. The cells were seeded at a density of $2 \times 10^{5}$ cells $/ \mathrm{ml}$ in complete RPMI-1640 containing 1X Cell Stimulation Cocktail plus protein transport inhibitors (Invitrogen; Thermo Fisher Scientific, Inc.) and incubated at $37^{\circ} \mathrm{C}$ for $16 \mathrm{~h}$. Following stimulation, the cells were washed in flow cytometry buffer (eBioscience) and were then incubated at $4^{\circ} \mathrm{C}$ for 30 min with the optimal concentration of PE/Cy7-conjugated anti-CD3mAb (cat.no.100219; 1:1,000),PerCP/Cy5.5-conjugated anti-CD11b mAb (cat. no. 101227; 1:1,000), APC-conjugated anti-CD27 mAb (cat. no. 124211; 1:1,000; all Biolegend, Inc., San Diego, CA, USA), FITC-conjugated anti-CD49b (cat. no. 11-5971-81; 1:1,000) and PE-conjugated anti-CD69 mAb (cat. no. 12-0691-82; 1:1,000; both eBioscience; Thermo Fisher Scientific, Inc.). To stain for intracellular IFN- $\gamma$, IL-5 and IL-13, the cells were fixed and permeabilized with Cytofix/Cytoperm (BD Biosciences) and then stained with anti-mouse IFN- $\gamma$ (cat. no. 12-7311-82; 1:1,000), IL-5 (cat. no. 12-7052-82; 1:1,000) and IL-13 mAb (cat. no. 12-7133-82; 1:1,000; all eBioscience; Thermo Fisher Scientific, Inc.). The cells were washed twice and then detected by flow cytometry (FACSCalibur; BD Biosciences) and analyzed using FlowJo 7.6 software (FlowJo LLC, Ashland, OR, USA).

Statistical analysis. Data are shown as the mean \pm standard error of the mean. Statistical significance of differences was determined with Student's unpaired two-tailed t-test. The software package GraphPad Prism 5 (GraphPad Software, Inc., La Jolla, CA, USA) was used for data analysis. $\mathrm{P}<0.05$ was considered to indicate a statistically significant difference.

\section{Results}

Successful establishment of a mouse allergic asthma model with OVA. Analysis of the inflammatory cells in the BALF samples revealed that the proportion of eosinophils was significantly increased following OVA challenge (Fig. 2A, green arrow), which constituted almost $50 \%$ of the total BALF cells (Fig. 2B). In addition, all mice challenged with OVA had increased total cell numbers and various inflammatory cell numbers in BALF in comparison with the PBS-challenged mice (Fig. 2B). On histological observation, the basement membrane of the bronchus specimens of the mice challenged with OVA became thickened compared with those of the control mice. Additionally, an increase in inflammatory cells around the airways was detected by repeated OVA challenge compared with the PBS control (Fig. 2C). By contrast, the OVA-challenged mice, but not the PBS-challenged mice, developed marked goblet cell hyperplasia and mucus hypersecretion 


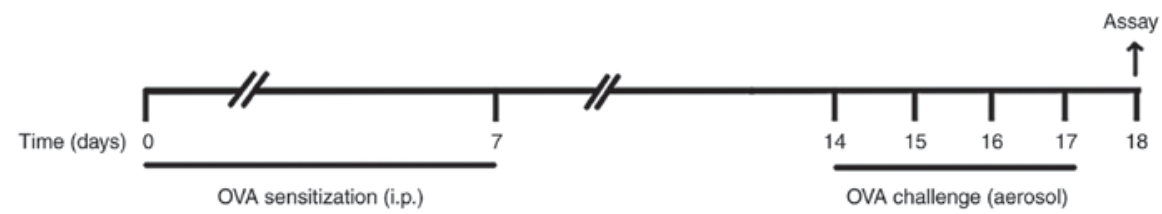

Figure 1. Asthma mouse model protocol. OVA, ovalbumin.

A

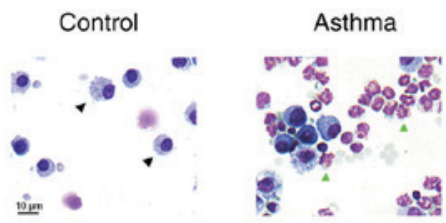

B

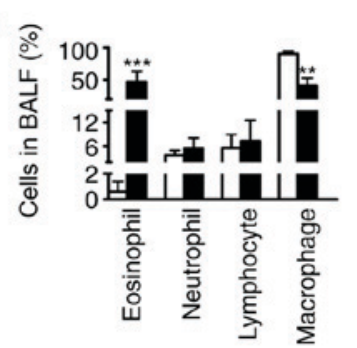

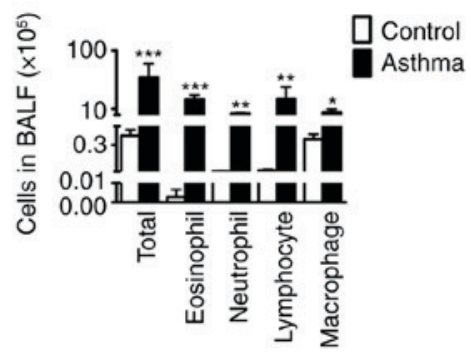

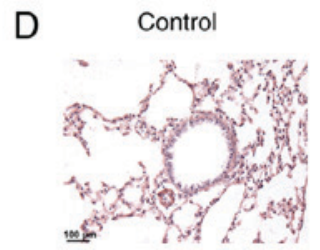

Asthma

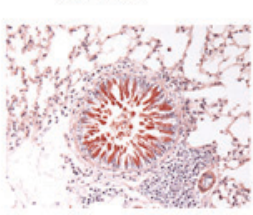

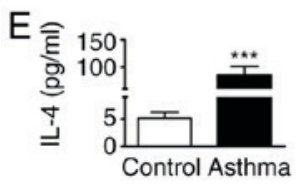
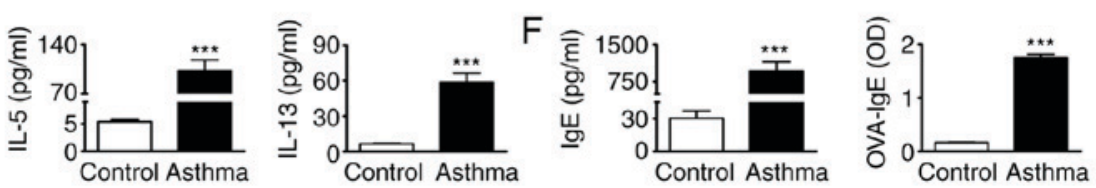

Figure 2. Successful establishment of an asthma model. (A) Wright-Giemsa staining shows the macrophages (black arrow) and eosinophils (green arrow) under microscopy (magnification, x400). (B) Statistical analysis of the numbers and proportions of eosinophils, neutrophils, macrophages and lymphocytes in BALF from sensitized mice $24 \mathrm{~h}$ following final last saline aerosol or OVA aerosol challenge. (C) Lung sections were stained with hematoxylin and eosin and (D) periodic acid-schiff, and examined under microscopy (magnification, x200). (E) Levels of IL-4, IL-5 and IL-13 in BALF and (F) IgE and OVA-IgE in serum were analyzed using ELISA $(n=6)$. ${ }^{*} \mathrm{P}<0.05,{ }^{* *} \mathrm{P}<0.01$ and ${ }^{* * *} \mathrm{P}<0.001$, vs. control group. OVA, ovalbumin; BALF, bronchoalveolar lavage fluid; IgE, immunoglobin E; IL, interleukin.

in the bronchi (Fig. 2D). Th2 cytokines have been considered to be the main orchestrator of the allergic airway inflammation underlying asthma (17). The results of the present study showed that OVA inhalation in sensitized mice caused marked increases in the levels of IL-4, IL-5 and IL-13 into the BALF compared with those in the PBS aerosol control (Fig. 2E). A crucial component of allergic immune responses is the production of $\operatorname{IgE}(18)$. Therefore, the levels of anti-IgE and OVA-specific IgE (OVA-IgE) were measured in serum of the OVA-challenged mice and PBS controls. The results demonstrated that the levels of anti-IgE and anti-OVA IgE were increased in the lungs of the OVA-challenged mice (Fig. 2F). Together, these data suggest that the mice sensitized and challenged with OVA were characterized by pathological asthma. Therefore, these mice were suitable for use as a model mice to investigate asthma.

Dynamic changes of $\mathrm{NK}$ cells in the development of asthma. NK cells reside in large numbers in the lungs, and are crucial in host survival by killing infected cells and/or producing cytokines (19). In the present study, the dynamic changes of NK cells were investigated during the development of asthma in the established OVA-induced mouse model. All the lymphocytes obtained from lungs were gated according to forward scatter (FSC) and side scatter (SSC), and NK cells $\left(\mathrm{CD}^{-}{ }^{-} \mathrm{DX}^{+}\right)$ within the lymphocytes were gated for the following analysis (Fig. 3A). The results showed that the proportion of NK cells in the lymphocytes was markedly decreased following OVA sensitization and challenge (Fig. 3B). Despite this, increased numbers of NK cells were observed in the asthma group compared with the control group (Fig. 3C). In addition, the activity of the NK cells was significantly enhanced following OVA treatment in the asthma group (Fig. 3D). The results showed that higher levels of IL- 5 and IL-13, rather than IFN- $\gamma$, were produced by the NK cells following OVA aerosol challenge (Fig. 3E). These data suggest that, although NK cells are not the crucial type of lymphocyte involved in asthma, they are likely to be involved in the development of asthma by secreting Th2 cytokines.

CD11b- CD27 NK cells are the primary NK subset which produce Th2 cytokines in asthma. Murine NK cells can be divided into four subsets according to the surface density of CD11b and CD27, the most immature subset is $\mathrm{CD}_{11 b^{-}} \mathrm{CD}_{27}$, followed by immature $\mathrm{CD}_{11} \mathrm{~b}^{-} \mathrm{CD} 27^{+}$, mature $\mathrm{CD} 11 \mathrm{~b}^{+} \mathrm{CD} 27^{+}$and the most

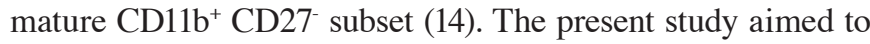
determine whether the lung NK cell phenotype was dynamically regulated with the development of asthma. The results showed that the percentages of the CD11b-CD27- NK and CD11b $\mathrm{CD} 27^{+} \mathrm{NK}$ subsets gradually increased during the development 
A

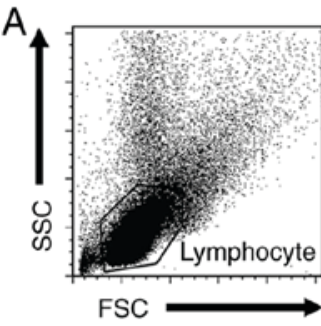

C

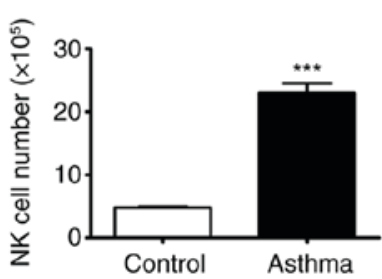

E
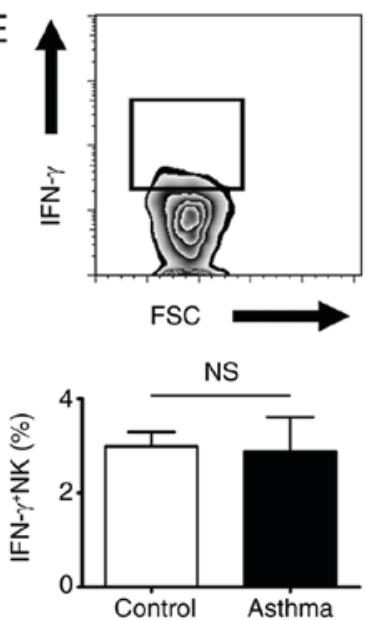
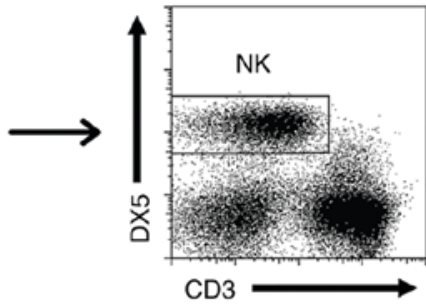

D

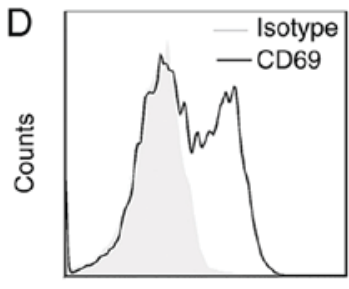

PE-CD69
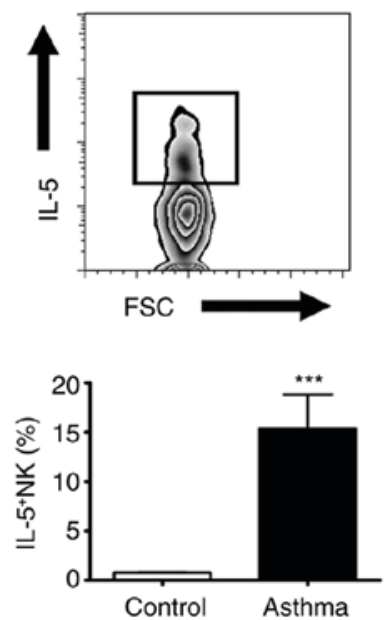

B
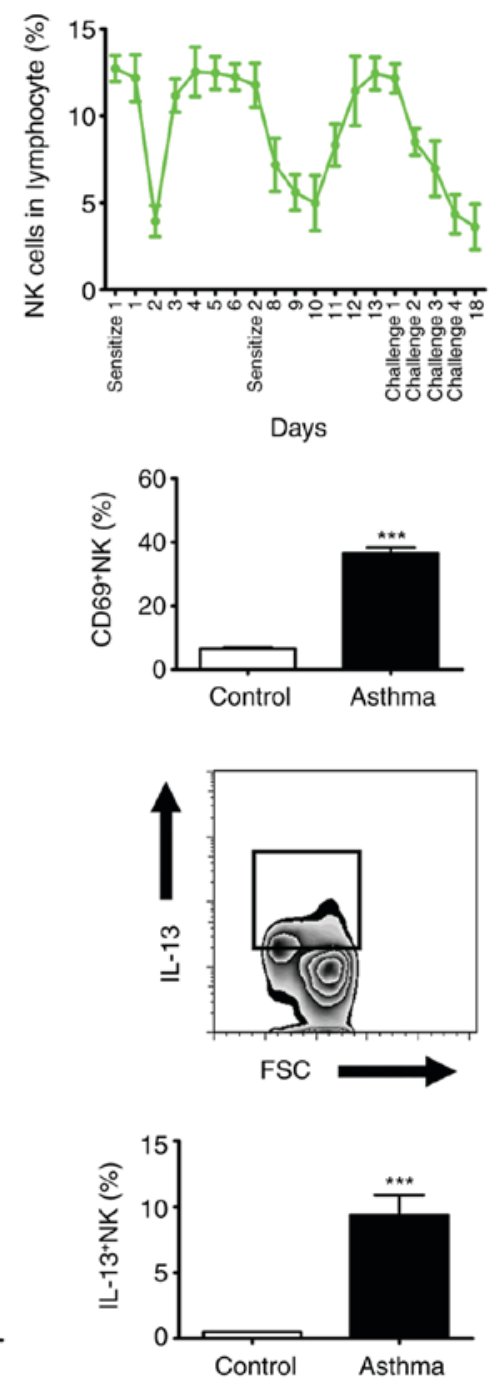

Figure 3. Dynamic changes of lung NK cells in the development of asthma. (A) NK cells were identified as a CD3- DX5 $5^{+}$cell population in a lymphocyte morphology gate on the basis of FSC and side scatter characteristics (violet box, left panel). (B) NK cells as a percentage of total lymphocytes were enumerated. (C) Absolute NK cell numbers obtained from lungs of BALB/c mice. (D) Representative flow cytometry plots showing the expression of CD69 on CD3- DX 5 ${ }^{+}$NK cells from the lungs obtained at day 18. (E) Representative flow cytometry plots showing the expression of IFN- $\gamma$, IL-5 and IL-13 on CD3-DX $5^{+}$NK cells from the lungs obtained at day $18(\mathrm{n}=6) .{ }^{* * * *} \mathrm{P}<0.001$, vs. control group. NK, natural killer; FSC, forward scatter; IFN, interferon; IL, interleukin; NS, not significant.

of asthma (Fig. 4A). By contrast, the percentages of the CD11 $\mathrm{b}^{+}$ $\mathrm{CD} 27^{+} \mathrm{NK}$ and $\mathrm{CD} 11 \mathrm{~b}^{+} \mathrm{CD} 27^{-} \mathrm{NK}$ subsets reduced with OVA sensitization and challenge (Fig. 4A). Subsequently, the cytokine secretion capacity of these NK subsets following OVA challenge was analyzed. Previous studies have suggested that immature NK cells are potent producers of cytokines and mature NK cells exhibit potent cytotoxic capabilities (15). Consistent with these findings, the results of the present study showed that CD11b ${ }^{-} \mathrm{NK}$

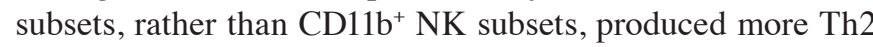
cytokines IL-5 and IL-13 following OVA challenge (Fig. 4B). Furthermore, the flow cytometry results showed that CD11b CD27 ${ }^{-} \mathrm{NK}$ cells were the primary NK subset that produces Th2 cytokines following OVA challenge (Fig. 4C). These findings collectively indicated that CD11b- CD27- $\mathrm{NK}$ cells may be the primary NK subset involved in the development of asthma.

\section{Discussion}

Allergic asthma has been considered to be driven by Th2 cytokines including IL-4, IL-5 and IL-13, which are important in orchestrating and amplifying allergic inflammation in asthma $(4,20)$. Th2 cells are considered the primary source of these cytokines (21). IL-4 promotes Th2 cell differentiation from uncommitted Th0 cells and $\mathrm{IgE}$ production by $\mathrm{B}$ cells $(22,23)$. IL-5 is known to drive eosinophil maturation and differentiation, goblet cell hyperplasia and mucus secretion (24). IL-13 has several actions similar to those of IL-4 by inducing IgE secretion, and has been implicated in airway remodeling, including mucus hypersecretion and goblet cell hyperplasia (25). Although evidence has clearly indicated the significance of Th2 cells in asthma, cumulative studies have revealed that innate lymphoid cells also have substantial involvement in asthma. Bronchial epithelial cells, which are the first line of defense against inhaled pathogens and particles, are important for allergen uptake and the initiation of allergic inflammation by releasing Th2-promoting cytokines, including IL-25, thymic stromal lymphopoietin and IL-33 (26). In addition, airway dendritic cells (DCs) are responsible for the initiation and maintenance of adaptive Th2 responses in asthma as they could recognize antigens through pattern recognition receptors such 

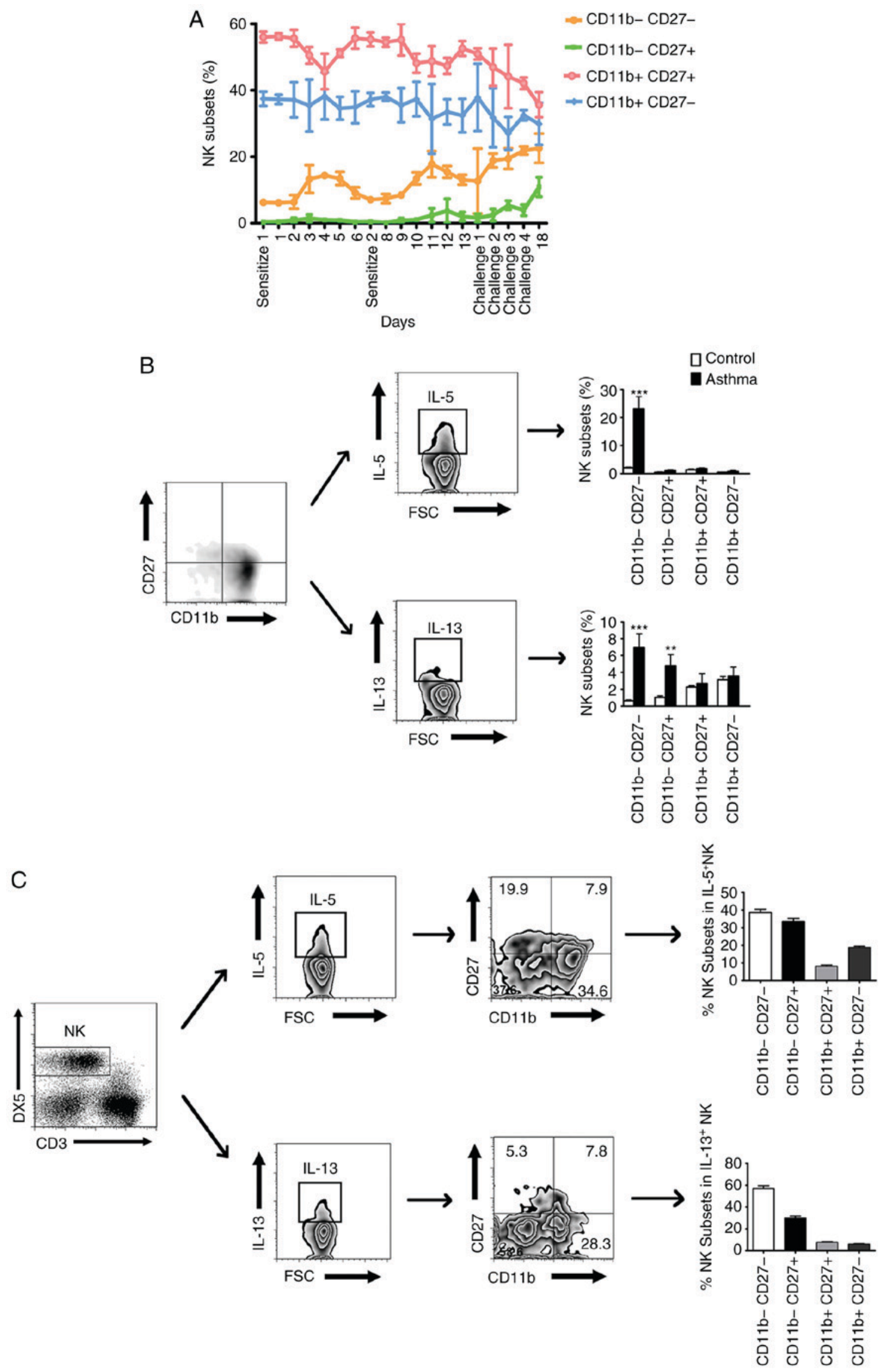

Figure 4. Dynamic changes of lung NK subsets in the development of asthma. (A) Percentages of the CD11b- CD27, CD11b- CD27+, CD11b+ CD27+ and $\mathrm{CD} 1 \mathrm{~b}^{+} \mathrm{CD} 27^{-}$subsets of NK cells obtained from the lung of mice $24 \mathrm{~h}$ following sacrifice. (B) Representative FACS histograms showing the expression of IL-5 and IL-13 in CD11b CD27, CD11b CD27+, CD11b ${ }^{+}$CD27 $7^{+}$and CD11b ${ }^{+}$CD27- subsets of NK cells, respectively. (C) Percentages of the IL-5 ${ }^{+}$and IL-13 ${ }^{+}$ NK cell subsets in total IL- $5^{+}$and IL-13+ $\mathrm{NK}$ cells, respectively $(\mathrm{n}=6){ }^{* * *} \mathrm{P}<0.01$ and ${ }^{* * * *} \mathrm{P}<0.001$, vs. control group. NK, natural killer; FSC, forward scatter; IL, interleukin. 
as TLRs and NLRs (27). The high frequency and number of NK cells in the lungs indicate the prominent role for these cells in the local immune system of the airways. In addition, the early response of NK cells to infection or antigens and subsequent interaction with other cells, including DCs, makes these cells potentially ideal candidates for influencing $\mathrm{T}$ cell responses. However, so far, the role of NK cells in asthma remains to be fully elucidated. Clinical investigations have shown that NK cells in the peripheral blood of patients with asthma were higher in number and exhibited higher cytotoxicity compared with healthy controls (28). With regard to animal models, several studies have indicated that NK cells may contribute to the initiation and development of allergic airway inflammation. Korsgren et al (29) found that the depletion of NK cells prior to OVA sensitization led to decreased production of Th2 cytokines and systemic IgE antibodies. However, anti-NK1.1 antibody may also knock out NK T cells, which have been demonstrated to be required for allergen-induced airway inflammation. Subsequently, Ple et al (30) showed that eosinophilic airway inflammation was reduced when NK cells were depleted following OVA challenge using anti-asialo GM1 antibodies. A later study by Mathias et al (31) observed that the depletion of NK cells using anti-Ly49 mAbs led to a decrease in airway inflammation, Th2 cytokine secretion and OVA-specific antibody production. Although the use of these antibodies did not influence NK T cells, GM1 and Ly49 are also expressed on $\mathrm{T}$ cell subsets. Together with experiments in mice, a requirement for NK cells in the development of asthma was revealed with these experiment methods. However, the mechanism of NK cells in asthma remains to be fully elucidated.

NK cells have a variety of biological effects, including exocytosis of cytotoxic granules and synthesis of cytokines (10). Although first identified by their cytotoxic activity against virally infected cells and tumors, NK cells also have a potent cytokine secretion capacity. Previous data have shown that NK cell cytokine production may be governed in part by the milieu during inflammation (32). As a general rule, NK cells secrete a large amount of IFN- $\gamma$ in response to IL-12 and IL-18 stimulation at an early stage of infection (33). However, in vitro experiments have revealed that NK cells in the spleen and liver also produce the IL-13 cytokine following co-stimulation with IL-18 and IL-12 (34). McDermott et al (35) demonstrated that NK cells secreted high levels of IL-13, which acted on the intestinal epithelial and led to the disruption of intestinal architecture in a mouse model of nematode infection. In addition, it has been observed that the NK cells from atopic patients with asthma released higher levels of IL-5 and IL-13 compared with healthy individuals (36). In the present study, it was found that NK cells secreted high levels of IL-5 and IL-13 in an OVA-induced mouse model of asthma. In addition, the percentage of lung NK cells in lymphocytes declined following OVA sensitization and challenge. These results support the previous conclusion that Th2 cells are the foremost cell types involved in asthma $(37,38)$. However, increased numbers and enhanced activity of NK cells were detected following OVA aerosol challenge in the experiments, which were consistent with the phenomenon observed clinically. Together, the data obtained in the present study and previous reports indicate that NK cells may be involved the development of asthma by producing Th2 cytokines.
It has been suggested that CD11b- CD27-, CD11b ${ }^{-}$CD $27^{+}$, $\mathrm{CD}_{11} \mathrm{~b}^{+} \mathrm{CD} 27^{+}$, and $\mathrm{CD} 11 \mathrm{~b}^{+} \mathrm{CD} 27^{-}$are discrete stages of $\mathrm{NK}$ cell in vivo maturation. The mature $\mathrm{NK}$ cells $\left(\mathrm{CD} 1 \mathrm{~b}^{+}\right)$make up the majority of NK cells circulating in peripheral blood and in non-lymphoid tissues, including the spleen and lung (12). These NK subsets have potent cytotoxic function and low cytokine production upon activation $(39,40)$. By contrast, immature NK cells $\left(\mathrm{CD} 1 \mathrm{~b}^{-}\right)$are most abundant within the bone marrow and lymph nodes and are efficient producers of cytokines $(41,42)$. Consistent with previous evidence, the results of the present study showed that the majority of lung NK cells within normal mice were $\mathrm{CD}_{11 b^{+}} \mathrm{NK}$ subsets, constituting $\sim 90 \%$ of the NK cells. These CD11b $\mathrm{b}^{+} \mathrm{NK}$ subsets gradually decreased following OVA induction whereas the immature CD11b- NK subsets increased, revealing that the changes in circumstance during the development of asthma have an impact on the NK subsets. Furthermore, the CD11b- NK subsets secreted more Th2 cytokines (IL-5 and IL-13) following OVA challenge, whereas the cytokine-producing capacity of the $\mathrm{CD} 11 \mathrm{~b}^{+} \mathrm{NK}$ subsets had no notable changes. These data demonstrated that immature NK cell subsets have an increased ability to secrete cytokines than mature NK cell subsets, as reported previously. Of note, the flow cytometry results showed that the CD11b CD27- NK cells are the primary NK subset that secrete Th2 cytokines, suggesting that the CD11b- CD27- NK cells may be the primary NK subset involved in the development of asthma.

In conclusion, the dynamic behavior of lung NK cells and their subsets during the development of asthma were analyzed in the present study. The results suggest that NK cells may be involved in the pathogenesis of asthma by secreting Th2 cytokines.

\section{Acknowledgements}

Not applicable.

\section{Funding}

This study was supported by grants from the National Natural Science Foundation of China (grant no. 81273305), the Basic Research Program of Science and Technology Plan of Shenzhen (grant no. JC201505280578A) and the Special Program of Construction National Innovative City of Shenzhen (grant no. 301201003010).

\section{Availability of data and materials}

The datasets used and/or analyzed during the current study are available from the corresponding author on reasonable request.

\section{Authors' contributions}

$\mathrm{ZC}$ and LW designed the project and performed the experiments. ZC wrote the manuscript.

\section{Ethics approval and consent to participate}

This study was approved by the Ethics Committee of Department of Immunology, School of Medicine, Shenzhen University. 


\section{Patient consent for publication}

Not applicable.

\section{Competing interests}

The authors declare they have no competing interests.

\section{References}

1. Jayasinghe H, Kopsaftis Z and Carson K: Asthma bronchiale and exercise-induced bronchoconstriction. Respiration 89: 505-512, 2015.

2. Reddel HK and Levy ML; Global Initiative for Asthma Scientific Committee and Dissemination and Implementation Committee: The GINA asthma strategy report: What's new for primary care? NPJ Prim Care Respir Med 25: 15050, 2015.

3. Becker AB and Abrams EM: Asthma guidelines: The global initiative for asthma in relation to national guidelines. Curr Opin Allergy Clin Immunol 17: 99-103, 2017.

4. Fajt ML and Wenzel SE: Asthma phenotypes and the use of biologic medications in asthma and allergic disease: The next steps toward personalized care. J Allergy Clin Immunol 135: 299-311, 2015.

5. Wenzel SE: Asthma phenotypes: The evolution from clinical to molecular approaches. Nat Med 18: 716-725, 2012.

6. Yu S, Kim HY, Chang YJ, DeKruyff RH and Umetsu DT: Innate lymphoid cells and asthma. J Allergy Clin Immunol 133: 943-951, 2014

7. DeKruyff RH, Yu S, Kim HY and Umetsu DT: Innate immunity in the lung regulates the development of asthma. Immunol Rev 260: 235-248, 2014.

8. Kim HY, DeKruyff RH and Umetsu DT: The many paths to asthma: Phenotype shaped by innate and adaptive immunity. Nat Immunol 11: 577-584, 2010.

9. McKenzie AN: Type-2 innate lymphoid cells in asthma and allergy. Ann Am Thorac Soc 11 (Suppl 5): S263-S270, 2014.

10. Campbell KS and Hasegawa J: Natural killer cell biology: An update and future directions. J Allergy Clin Immunol 132: 536-544, 2013.

11. Varchetta S, Oliviero B, Mavilio D and Mondelli MU: Different combinations of cytokines and activating receptor stimuli are required for human natural killer cell functional diversity. Cytokine 62: 58-63, 2013.

12. Ndhlovu LC, Lopez-Vergès S, Barbour JD, Jones RB, Jha AR, Long BR, Schoeffler EC, Fujita T, Nixon DF and Lanier LL: Tim-3 marks human natural killer cell maturation and suppresses cell-mediated cytotoxicity. Blood 119: 3734-3743, 2012.

13. Messaoudene M, Fregni G, Fourmentraux-Neves E, Chanal J, Maubec E, Mazouz-Dorval S, Couturaud B, Girod A, Sastre-Garau X, Albert S, et al: Mature cytotoxic CD56(bright)/CD16(+) natural killer cells can infiltrate lymph nodes adjacent to metastatic melanoma. Cancer Res 74: 81-92, 2014.

14. Chiossone L, Chaix J, Fuseri N, Roth C, Vivier E and Walzer T: Maturation of mouse NK cells is a 4-stage developmental program. Blood 113: 5488-5496, 2009.

15. Holmes ML, Huntington ND, Thong RP, Brady J, Hayakawa Y, Andoniou CE, Fleming P, Shi W, Smyth GK, Degli-Esposti MA, et al: Peripheral natural killer cell maturation depends on the transcription factor Aiolos. EMBO J 33 2721-2734, 2014

16. Chen Z, Chen X, Xu Y, Xiong P, Fang M, Tan Z, Gong F and Zheng F: Collagenase digestion down-regulates the density of CD27 on lymphocytes. J Immunol Methods 413: 57-61, 2014

17. Allan RS, Zueva E, Cammas F, Schreiber HA, Masson V, Belz GT, Roche D, Maison C, Quivy JP, Almouzni G and Amigorena S: An epigenetic silencing pathway controlling T helper 2 cell lineage commitment. Nature 487: 249-253, 2012.

18. Gray LEK and Sly PD: Update in asthma 2017. Am J Respir Crit Care Med 197: 1108-1115, 2018.

19. Poli A, Michel T, Patil N and Zimmer J: Revisiting the functional impact of NK cells. Trends Immunol 39: 460-472, 2018.

20. Peters SP: Asthma phenotypes: Nonallergic (intrinsic) asthma J Allergy Clin Immunol Pract 2: 650-652, 2014.

21. Schatz M and Rosenwasser L: The allergic asthma phenotype. J Allergy Clin Immunol Pract 2: 645-649, 2014.
22. Steinke JW and Borish L: Th2 cytokines and asthma. Interleukin-4: Its role in the pathogenesis of asthma and targeting it for asthma treatment with interleukin-4 receptor antagonists. Respir Res 2: 66-70, 2001

23. Munitz A, Brandt EB, Mingler M, Finkelman FD and Rothenberg ME: Distinct roles for IL-13 and IL-4 via IL-13 receptor alpha1 and the type II IL-4 receptor in asthma pathogenesis. Proc Natl Acad Sci USA 105: 7240-7245, 2008

24. Rosenwasser LJ and Rothenberg ME: IL-5 pathway inhibition in the treatment of asthma and Churg-Strauss syndrome. J Allergy Clin Immunol 125: 1245-1246, 2010.

25. Ingram JL and Kraft M: IL-13 in asthma and allergic disease: Asthma phenotypes and targeted therapies. J Allergy Clin Immunol 130: 829-844, 2012.

26. Lambrecht $\mathrm{BN}$ and Hammad H: Asthma and coagulation. N Engl J Med 369: 1964-1966, 2013.

27. van Helden MJ and Lambrecht BN: Dendritic cells in asthma. Curr Opin Immunol 25: 745-754, 2013.

28. Deniz G, van de Veen W and Akdis M: Natural killer cells in patients with allergic diseases. J Allergy Clin Immunol 132: 527-535, 2013

29. Korsgren M, Persson CG, Sundler F, Bjerke T, Hansson T, Chambers BJ, Hong S, Van Kaer L, Ljunggren HG and Korsgren O: Natural killer cells determine development of allergen-induced eosinophilic airway inflammation in mice. J Exp Med 189: 553-562, 1999.

30. Ple C, Barrier M, Amniai L, Marquillies P, Bertout J, Tsicopoulos A, Walzer T, Lassalle P and Duez C: Natural killer cells accumulate in lung-draining lymph nodes and regulate airway eosinophilia in a murine model of asthma. Scand J Immunol 72: 118-127, 2010

31. Mathias CB, Guernsey LA, Zammit D, Brammer C, Wu CA, Thrall RS and Aguila HL: Pro-inflammatory role of natural killer cells in the development of allergic airway disease. Clin Exp Allergy 44: 589-601,2014.

32. Perricone R, Perricone C, De Carolis C and Shoenfeld Y: NK cells in autoimmunity: A two-edg'd weapon of the immune system. Autoimmun Rev 7: 384-390, 2008.

33. Haeberlein S, Sebald H, Bogdan C and Schleicher U: IL-18, but not IL-15, contributes to the IL-12-dependent induction of NK-cell effector functions by Leishmania infantum in vivo. Eur J Immunol 40: 1708-1717, 2010.

34. Hoshino T, Winkler-Pickett RT, Mason AT, Ortaldo JR and Young HA: IL-13 production by NK cells: IL-13-producing NK and T cells are present in vivo in the absence of IFN-gamma. J Immunol 162: 51-59, 1999.

35. McDermott JR, Humphreys NE, Forman SP, Donaldson DD and Grencis RK: Intraepithelial NK cell-derived IL-13 induces intestinal pathology associated with nematode infection. J Immunol 175: 3207-3213, 2005.

36. Aktas E, Akdis M, Bilgic S, Disch R, Falk CS, Blaser K, Akdis C and Deniz G: Different natural killer (NK) receptor expression and immunoglobulin $\mathrm{E}$ (IgE) regulation by NK1 and NK2 cells. Clin Exp Immunol 140: 301-309, 2005.

37. Fahy JV: Type 2 inflammation in asthma-present in most, absent in many. Nat Rev Immunol 15: 57-65, 2015.

38. Holgate ST: Innate and adaptive immune responses in asthma. Nat Med 18: 673-683, 2012.

39. Sceneay J, Chow MT, Chen A, Halse HM, Wong CS, Andrews DM, Sloan EK, Parker BS, Bowtell DD, Smyth MJ and Möller A: Primary tumor hypoxia recruits CD11b+/Ly6Cmed/Ly6G+ immune suppressor cells and compromises NK cell cytotoxicity in the premetastatic niche. Cancer Res 72: 3906-3911, 2012

40. Yanagisawa K, Exley MA, Jiang X, Ohkochi N, Taniguchi M and Seino K: Hyporesponsiveness to natural killer T-cell ligand alpha-galactosylceramide in cancer-bearing state mediated by CD11b+ Gr-1+ cells producing nitric oxide. Cancer Res 66: 11441-11446, 2006

41. Clinthorne JF, Beli E, Duriancik DM and Gardner EM: NK cell maturation and function in $\mathrm{C} 57 \mathrm{BL} / 6$ mice are altered by caloric restriction. J Immunol 190: 712-722, 2013.

42. Mao Y, Sarhan D, Steven A, Seliger B, Kiessling R and Lundqvist A: Inhibition of tumor-derived prostaglandin-e2 blocks the induction of myeloid-derived suppressor cells and recovers natural killer cell activity. Clin Cancer Res 20: 4096-4106, 2014.

This work is licensed under a Creative Commons Attribution-NonCommercial-NoDerivatives 4.0 International (CC BY-NC-ND 4.0) License. 